\title{
Anatomic variations of the nose and paranasal sinuses in saudi population: computed tomography scan analysis Nada Alshaikh ${ }^{\mathrm{a}}$, Amirah Aldhurais ${ }^{\mathrm{b}}$
} aDepartment of Otolaryngology Head \& Neck
Surgery, Rhinology Unit, Dammam Medical
Complex (DMC), 'b Department of ENT, King
Fahad Specialist Hospital (KFSH), Dammam,
Saudi Arabia

Correspondence to Nada Alshaikh, MD Department of Otorhinolaryngology Head and Neck Surgery, Dammam Medical Complex, Dammam - 31414, Saudi Arabia

e-mail: nadaats@yahoo.com

Received 13 November 2016 Accepted 23 December 2016

The Egyptian Journal of Otolaryngology 2018, 34:234-241

\begin{abstract}
Background
Knowledge of the anatomy constitutes an integral part in the total management of patients with sinonasal diseases. The aim of this study was to obtain the prevalence of sinonasal anatomic variations in Saudi population and to understand their importance and impact on the disease process, as well as their influence on surgical management and outcome.

Materials and methods

This study is prospective review of retrospectively performed normal computed tomography (CT) scans of the nose and paranasal sinuses in adult Saudi population at Dammam Medical Complex. The scans were reviewed by two independent observers.

\section{Results}

Of all CT scans that were reviewed, $48.4 \%$ were of female patients and $51.6 \%$ were of male patients. The mean age of the study sample was $38.5 \pm 26.5$ years.

The most common anatomic variation after excluding agger nasi cell was pneumatized crista galli, which was seen in $73 \%$ of the scans. However, the least common variation seen in this series was hypoplasia of the maxillary sinus, which was encountered in $5 \%$ of the cases. We did not detect a single pneumatized inferior turbinate among the studied scans.

\section{Conclusion}

A wide range of regional differences in the prevalence of each anatomic variation exists. Understanding the preoperative CT scan is substantially important because it is the road map for the sinus surgeon. Detection of anatomic variations is vital for surgical planning and prevention of complications.
\end{abstract}

\footnotetext{
Keywords:

Egypt J Otolaryngol 34:234-241

(c) 2018 The Egyptian Journal of Otolaryngology

$1012-5574$
}

agger nasi, anatomic variations, computed tomography scan, concha bullosa, cristal galli, haller cell, middle turbinate, nasal septum, nose and paranasal sinuses, onodi cell

\section{Introduction}

The superiority of computed tomography (CT) scan compared with conventional radiography has unquestionable importance for the evaluation of anatomic structure and pathology [1].

Nowadays, both radiologists and otolaryngologists depend on CT scan as the radiological modality of choice for the evaluation of the nose and paranasal sinuses [2].

CT scan has the ability to detect fine bone architecture of the nasal cavity and paranasal sinuses, the mucosa, and the air, thus making it a preferred tool for imaging [3]. Using multiplanar reformatted imaging of the sagittal and coronal views will help in identifying the anatomic variation in paranasal sinuses and eliminating the artifacts. In addition, using bone and soft tissue windows may help in the evaluation of dehiscence abnormalities [4]. It is essential to perform CT scan of the paranasal sinuses before attempting sinonasal surgery, to avoid potential complications resulting from unrecognized important anatomical landmarks and significant anatomic variations [5].

In the advanced era of endoscopic sinus and skull base surgery, a thorough knowledge of the precise anatomy and common anatomic variation of the nose and paranasal sinuses and the relation with the neighboring structures constitute an integral part of the total diagnostic and therapeutic management of patients with sinonasal disease [6,7]. As such, a detailed preoperative checklist evaluation of the sinonasal CT scan enhances the safety and efficacy of the nose and paranasal sinus surgery [8].

CT scan will help the otolaryngologist in understanding the complex anatomy, which could cause the sinonasal symptoms. In addition, it will

This is an open access journal, and articles are distributed under the terms of the Creative Commons Attribution-NonCommercial-ShareAlike 4.0 License, which allows others to remix, tweak, and build upon the work non-commercially, as long as appropriate credit is given and the new creations are licensed under the identical terms. 
help in identifying the landmarks that play a significant role for orientation during endoscopic sinus surgeries (ESSs) and aid in performing successful surgery with avoidance of serious complications [9].

Although anatomic variation in the sinonasal region is not uncommon [10], it was found that the frequency of these variations may differ among the different ethnic groups [11].

The purpose of this study was to determine the background of the prevalence of the most common anatomic variations in the nose and paranasal sinuses among adults of Saudi Arabia and to compare our results with other published data.

\section{Materials and methods}

We conducted a prospective review of retrospectively performed normal CT scans of the nose and paranasal sinuses in adult Saudi population. Patients consent for emolument in the study was obtained prior to the review. The study was conducted at the Otolaryngology Department of an advanced secondary hospital in Saudi Arabia.

In this study, we reviewed a total of 942 consecutive $\mathrm{CT}$ scans of the paranasal sinuses over a period of 5 years. Of all CT scans reviewed, only 219 were normal adult CT scans that met our inclusion criteria. The older 89 CT scans were performed using a Multichannel Toshiba (Asteion 4, AMBER Diagnostics, Orlando, Florida, USA) scanner. The specifications of the technique include $3 \mathrm{~mm}$ section thickness, interval direct coronal and axial imaging, $250 \mathrm{~mA}, 120 \mathrm{kV}, 1 \mathrm{~s}$ scan time, $16 \mathrm{~cm}$ display field of view, and a window of 2000 and $250 \mathrm{HU}$.

The rest of the CT scans were performed with a helical multislice GE scanner (GE, Standish, Maine, USA). Specification of this device includes $0.63-1 \mathrm{~mm}$ section thickness and interval direct coronal and axial cuts. Images were installed and archived from the Picture Archiving Communication System (PACS) software.

CT scans were reviewed by independent observers. First review and reporting was performed by the radiology consultants who follow an approved departmental CT sinuses template in reporting, which reduces the interobserver variability. Second review was performed by the second author, who is a senior rhinology consultant.

We excluded patients who were less than 12 years of age, those of non-Saudi nationality, patients who had previously undergone nasal or paranasal sinus surgery, and those who presented with extensive sinonasal disease, tumors, or fractures.

Anatomic variations that have been investigated include the following: variations of the nasal septum (deviation, spur, and pneumatization), pneumatization of the crista galli, variations of the turbinates (inferior turbinate pneumatization, paradoxical middle turbinate, and pneumatized middle turbinate), variations of the maxillary sinus (hypoplasia and presence of septation), variations of the frontal sinus (aplasia and hypoplasia), and presence of variants of specific ethmoidal sinus cells (agger nasi cell, Haller's cell, and Onodi cell).

Data recording and statistical analysis were carried out using Excel Microsoft Workbook for Mac 2011 (Apple Inc., Sunnyvale, California, USA) version 14.0.2. The study was approved by the local institutional research and ethics committee.

\section{Results}

A total of 942 consecutive CT scans of the paranasal sinuses were reviewed over a period of 5 years, of which 623 were excluded. Reasons for exclusion include the presence of sinonasal disease in 348 scans, no images available in 140 scans, non-Saudi nationality in 56 scans, improper CT cuts in 49 scans, history of previous sinonasal surgery in 22 cases, and pediatric

Figure 1

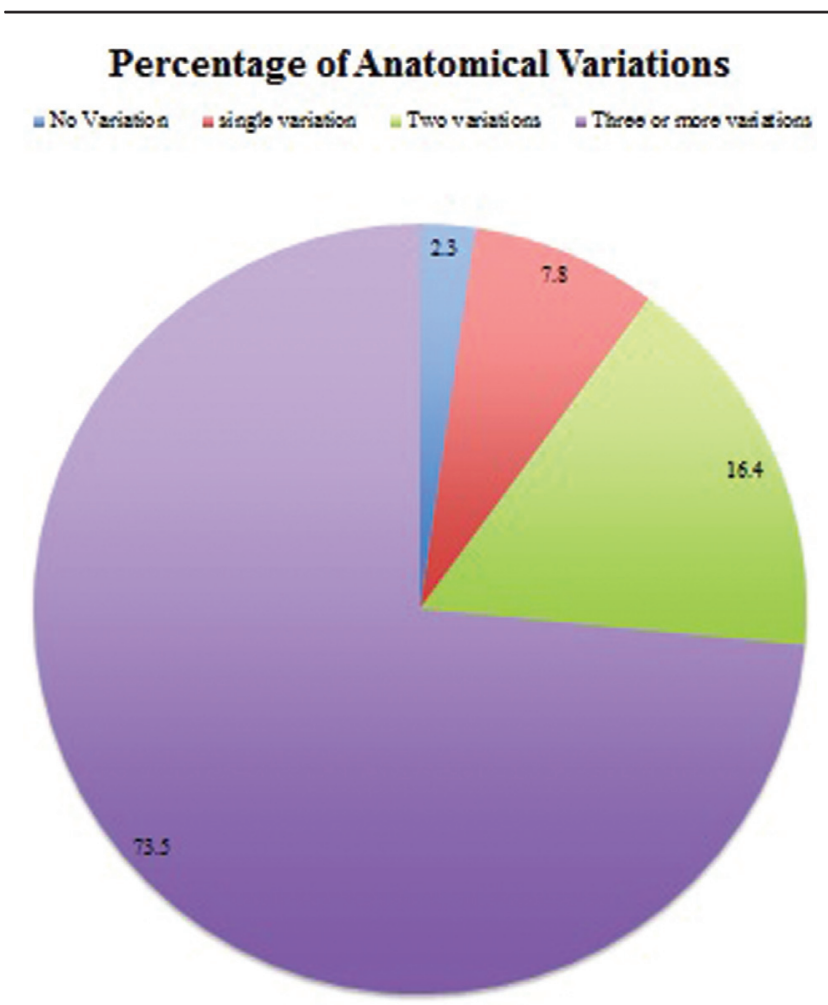

Percentage of anatomic variations after exclusion of agger nasi cell 
Figure 2
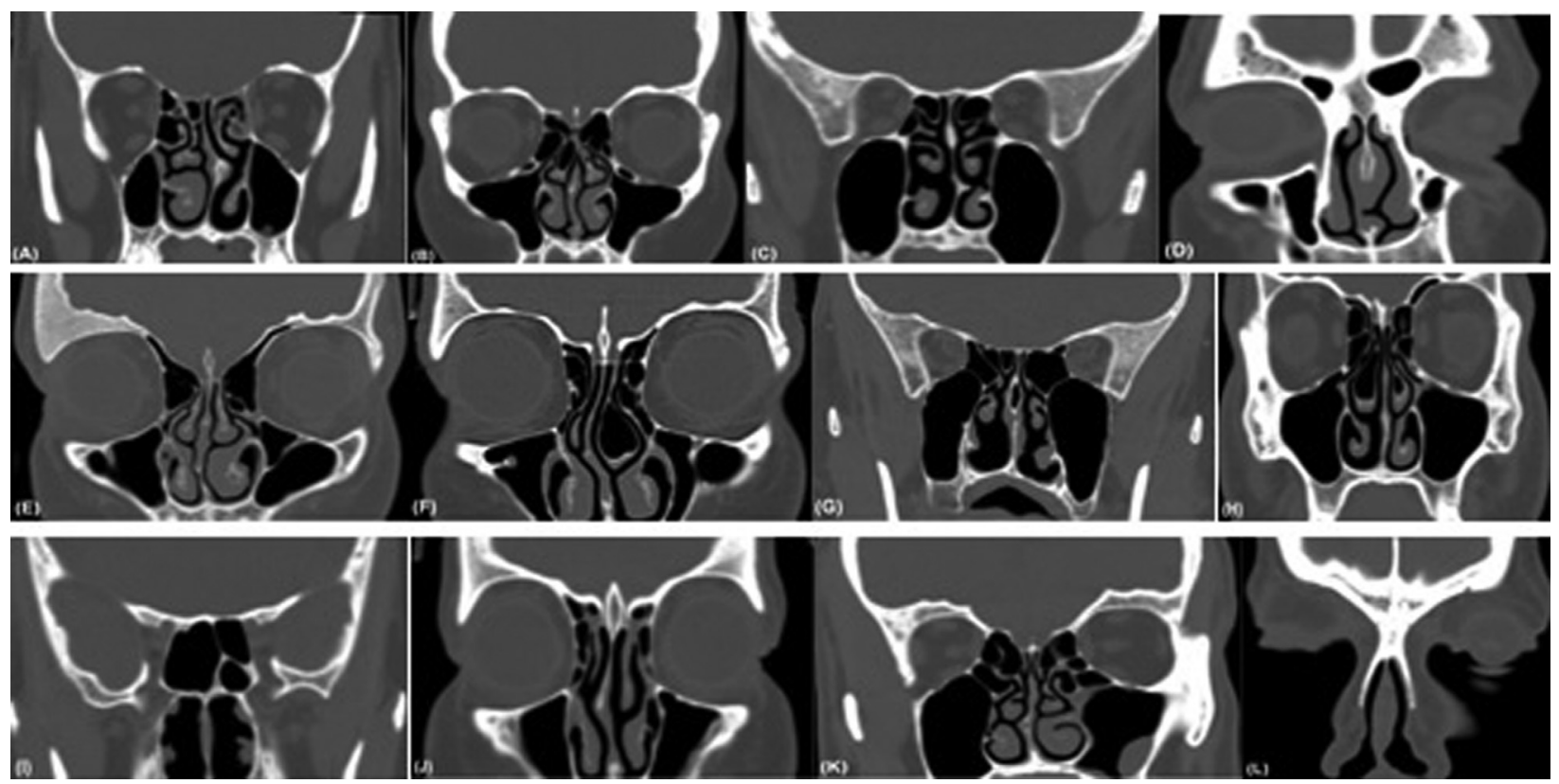

(a) Maxillary hypoplasia; (b) Haller's cell; (c) septal spur; (d) frontal hypoplasia; (e) maxillary septum; (f) deviated nasal septum and concha bullosa; (g) pneumatized septum; (h) concha bullosa; (i) Onodi cell (j) pneumatized crista galli; (k) paradoxical middle turbinate; (l) frontal agenesis

patient in eight cases. The 219 included scans were of Saudi adults with clear paranasal sinuses or minimal mucosal disease and with no history of previous sinonasal surgery. All CT scans were requested by otolaryngologists to rule out sinonasal disease. The mean age of the study sample was $38.5 \pm 26.5$ years; 106 (48.4\%) were female patients and 113 (51.6\%) were male patients.

After exclusion of the agger nasi cell, which was found to be constant in the entire study sample, we have found that there was no single anatomic variation detected in five (2.3\%) patients, single anatomic variation was found in $17(7.8 \%)$ patients, two anatomical variations in $36(16.4 \%)$ patients, and three or more anatomic variations in the remaining $161(73.5 \%)$ patients (Fig. 1).

Agger nasi cell was found in the entire study sample bilaterally. The most common anatomic variation after excluding agger nasi cell was pneumatized crista galli, which was seen in $73 \%$ of the scans. However, the least common variation seen in this series was hypoplasia of the maxillary sinus, which was encountered in $5 \%$ of the cases. We did not detect a single pneumatized inferior turbinate among the studied scans. Different identified anatomic variations are seen in Figure 2.

The frequency and prevalence of the different anatomic variations are summarized in Table 1.
Table 1 Frequency and prevalence of various anatomical variations

\begin{tabular}{lc}
\hline Variants & $n(\%)$ \\
\hline Agger nasi cell & $219(100)$ \\
Pneumatized crista galli & $160(73)$ \\
Pneumatized middle turbinate & $97(44.3)$ \\
Deviated nasal septum & $85(38.8)$ \\
Haller's cell & $71(32.4)$ \\
Septal spur & $70(32)$ \\
Frontal hypoplasia & $59(26.9)$ \\
Paradoxical middle turbinate & $54(24.7)$ \\
Pneumatized septum & $33(15)$ \\
Onodi cell & $25(11.4)$ \\
Maxillary sinus septum & $19(8.6)$ \\
Frontal agenesis & $16(7.3)$ \\
Maxillary hypoplasia & $11(5)$ \\
Pneumatized inferior turbinate & $0(0)$ \\
\hline
\end{tabular}

\section{Discussion}

ESS is a minimal invasive procedure that has been introduced as a valuable option in the management of sinunasal diseases [12]. The success, outcome, and completeness of ESS procedure are directly related to the understanding of sinus anatomy [13]. As such, it is substantially important for otolaryngologists to study the detailed normal anatomy and anatomic variations of the nose and paranasal sinuses for each individual patient before ESS [14].

In this report, we studied different important anatomic variations in the nose and paranasal sinuses in adult 
Saudi patients and we compared our results with other reports in the literature.

There is a significant body of literature supporting the link between the presence of anatomic variations and development of sinonasal disease [15].

The overall prevalence of anatomic variations in our study is higher than that reported in the literature. This was not expected as our study population has no or very minimal sinus disease. Such an unexpected result could be due to the difference in population size, the difference in selecting the studied CT scans (disease, undiseased, or mixed group), the number and nature of included anatomical variations, the quality and standards of the $\mathrm{CT}$ scan used, and the subjectivity in reading the $\mathrm{CT}$ images. In addition, it has been reported that ethnic differences may influence the prevalence of some anatomic variations in the sinonasal region [11].

Badia et al. [11] reported a significantly higher incidence of sphenoethmoid cells (Onodi cells) in the Chinese population in comparison with the Caucasian population.

In a different report, Cho et al. [16] found a significantly low incidence of supraorbital ethmoid cell in the Korean population at $2.6 \%$ compared with $64.6 \%$ in the white population, which could be attributed to the pronounced glabella and superior orbital rim found in Caucasians.

The difference in the prevalence of anatomical variation in our study population and others reported in the literature can be seen in Tables 2-4.

In this study, we have utilized specific definitions for the variations in nasal cavity and paranasal sinuses. In addition, we highlighted the clinical significance of each one of them.

\section{Nasal septum}

In this study, deviated nasal septum (DNS) was considered as any aching of the septum either osseous,

Table 2 Prevalence of anatomic variation in different studies

\begin{tabular}{lcl}
\hline References & $\begin{array}{c}\text { \% anatomic } \\
\text { variations }\end{array}$ & Remarks \\
\hline This study & 98.9 & $\begin{array}{l}\text { Saudi population } \\
\text { Adeel et al. [13] }\end{array}$ \\
Pérez-Piñas et al. [17] & 67.9 & $\begin{array}{l}\text { Pakistani } \\
\text { population } \\
\text { Spanish sinus } \\
\text { population } \\
\text { Nonsinus and sinus } \\
\text { groups }\end{array}$ \\
Zinreich [18] & $13-62$ & $\begin{array}{l}\text { Sinus patients } \\
\text { Earwaker [19] }\end{array}$ \\
Bolger et al. [6] & 93 & Nonsinus \\
Al-Abri et al. 2014 [20] & 64.9 & -
\end{tabular}

cartilaginous, or osseocartilaginous that blocks at least half of the nasal cavity [13].

However, septal spur was considered as any sharp angulation of the septum recognized in CT scan [7]. Nasal septal deviations and nasal spurs if large or severe may lateralize the middle turbinate by pressure effect and thus narrow the middle meatus, consequently leading to inflammation and infection [21]. This may be considered as a predisposing factor for obstruction of the normal mucous flow leading to inflammation and infection [33].

By far, DNS is the most frequent anatomical variant encountered in the nasal cavity. In our study, we encountered DNS in $38.8 \%$ of the scans. As illustrated in Table 3, the wider the definition of DNS, the higher the prevalence of such a variation to the extent that it might be considered as a normal finding rather than a variant of the normal [26]. The lower prevalence can be attributed to the fact that only severely angulated nasal septum that impinges on adjacent structures was considered as DNS [23].

Pneumatization of the septum, however, is considered a common finding in the posterior superior aspect of the septum [7]. It usually communicates and drains into the sphenoid sinus [34]. When diseased, it may resemble an encephalocele, for which CT scan and MRI are needed to confirm the diagnosis [7].

\section{Crista galli}

It is a well-recognized phenomenon in which the crista galli, which is normally a bony structure, becomes aerated [7]. We considered any degree of aeration of the crista galli in this study as a positive finding. Sometimes, it is recognized as a double bony structure with no air in between. In this case, it was not considered as pneumatized crista galli. In our study, pneumatized crista galli was the most common anatomic variation encountered.

It has been reported that pneumatized crista galli usually communicates with the frontal sinus and drains through the frontal recess [7]. Any obstruction of its drainage pathway might lead to infection and development of mucocele, which can be - if not recognized preoperatively - mistaken as an ethmoid cell and lead to an accidental invasion of the skull base during surgery [7].

\section{Middle turbinate}

A concha bullosa is an extension of pneumatization from either the anterior (55\%) or posterior (45\%) 
Table 3 Prevalence of the anatomic variations of the nasal septum, crista galli, and middle turbinate variations with comparison with some literature reports

\begin{tabular}{|c|c|c|c|c|c|c|}
\hline \multirow[t]{2}{*}{ References } & \multicolumn{6}{|c|}{$\%$ Variant } \\
\hline & DNS & Spur & Aerated septum & Aerated CG & Concha bullosa & Paradoxic MT \\
\hline This study & 38.8 & 32 & 15 & 73 & 44.3 & 24.7 \\
\hline Al-Abri etal. [20] & 80 & - & - & - & 49 & 13 \\
\hline Midilli etal. [4] & - & - & - & - & 37 & 12 \\
\hline Kayalioglu etal. [21] & 17 & - & 4 & 6 & 28 & 10 \\
\hline Pérez-Piñas etal. [17] & 58 & 14 & - & - & 24.5 & 10 \\
\hline Basić etal. [22] & - & - & - & 2.4 & - & - \\
\hline Earwaker [19] & 44 & 22.5 & 26 & 7.5 & 55 & - \\
\hline Bolger etal. [6] & - & - & - & - & $53(46,31,15)$ & - \\
\hline Calhoun etal. [23] & 40 & - & - & - & 29 & 12 \\
\hline Blaugrund [24] & 20 & - & - & - & - & - \\
\hline Zinreich etal. [7] & - & - & - & - & $34(55)$ & - \\
\hline Goldman [25] & - & - & - & - & 80 & - \\
\hline Takanishi [26] & 96.9 & - & - & - & - & - \\
\hline Ritter [27] & - & - & - & - & 15 & - \\
\hline
\end{tabular}

CG, crista galli; DNS, deviated nasal septum; MT, middle turbinate.

Table 4 Prevalence of the anatomic variations of the agger nasi cell, Haller's cell, Onodi cell, maxillary sinus, and frontal sinus with comparison with some literature reports

\begin{tabular}{|c|c|c|c|c|c|c|c|}
\hline \multirow[t]{2}{*}{ References } & \multicolumn{7}{|c|}{$\%$ Variant } \\
\hline & Agger nasi cell & Haller's cell & Onodi cell & Hypoplastic MS & Septated MS & Aplastic FS & Hypoplastic FS \\
\hline This study & 100 & 32.4 & 11.4 & 5 & 8.6 & 7.3 & 26.9 \\
\hline Rashed etal.[20] & 49 & 24 & 7.5 & - & - & - & - \\
\hline Adeel etal.[13] & - & 9.1 & 7.8 & - & - & - & - \\
\hline Mazza etal.[28] & - & 4 & - & - & - & - & - \\
\hline Selcuk etal.[29] & - & - & - & 4.6 (13) & 22.8 & - & - \\
\hline Midilli etal.[4] & - & - & - & 4 & 2 & 4.2 & 14.1 \\
\hline Pinas etal.[17] & 85 & 3 & 11 & 6.3 & - & - & - \\
\hline Kayalioglu etal.[21] & 6.4 & $5(3.7-5.5)$ & - & - & - & - & - \\
\hline Jensen etal.[30] & - & - & - & - & 28 & - & - \\
\hline Earwaker [19] & 96 & 21 & $24(75)$ & - & 1 & 5 & 4 \\
\hline Bolger etal.[6] & - & 46 & - & 10.4 & $2-4$ & - & - \\
\hline Schaefer [31] & 10 & - & 10 & - & - & - & - \\
\hline Kennedy-Zinreich[32] & 100 & 28 & 13.8 & - & - & - & - \\
\hline
\end{tabular}

FS, frontal sinus; MS, maxillary sinus.

ethmoid air cells [6]. It is one of the most frequently studied variant seen in patients with sinusitis [35].

Its prevalence ranges between 4 and $80 \%$ depending on the criteria for pneumatization and the differences in study populations [33].

Bolger, in 1991, studied the different patterns of concha bullosa and classified them according to the area of pneumatization into three types: aeration of the vertical lamella, the bulb, and the whole middle turbinate. He found a high prevalence of aeration of the vertical lamella compared with low prevalence of whole middle turbinate pneumatization [6].

For the sake of this study, we adopted the following definition: any pneumatization of the middle turbinate regardless of which part or of what size is a concha bullosa [7]. In this report, it was as frequent as $44.3 \%$. The vast majority was unilateral.

The highest percentage of detected concha bullosa was reported by Goldman in 1987 and it was based on anatomic dissection of the middle turbinate specimens of patients who underwent surgery and middle turbinate was amputated [25].

Paradoxical middle turbinate is when the turbinate curvature projects laterally and thus narrows the middle meatus and infundibulum [7]. This variation is not associated with any change in the middle turbinate attachment, and regardless of the size of the turbinate the majority was unilateral [19].

In our study, it was found to be $24.7 \%$, which is also the highest on comparing with other studies. 
When the concha bullosa is very large or when the middle turbinate is paradoxical, it can obstruct the middle meatus and infundibulum, thus predisposing for the development of rhinosinusitis [7]. Further, the concha bullosa would react similar to any other air cell in the sinonasal region, and if its drainage gets obstructed mucocele could happen [7]. It is usually asymptomatic, but it can cause symptoms such as headache and nasal obstruction when it has extensive aeration [36].

However, Zinrech [7] in his study failed to demonstrate an increase in the ostiomeatal complex disease among those with concha bullosa compared with those without.

\section{Ethmoid cells}

Agger nasi cell is defined as the most anterior ethmoid air cell located below the frontal sinus and extends to the frontal recess superiorly and anteriorly and arches the lacrimal fossa inferolaterally [32]. It is clinically significant due to its location relevant to the frontal recess and the lacrimal sac [33].

If it is extensively pneumatized or diseased, it may obstruct frontal sinus drainage, leading to frontal sinusitis or ocular symptoms [14]. It also provides a surgical access to the frontal recess area and the frontal sinus during ESS [33]. The prevalence of agger nasi cell varies widely between investigators, ranging between 3 [37] and 100\% [32]. In our study, agger nasi cell was a constant finding in all CT studies we reviewed.

Haller's cell, however, was first described by Albert Von Haller in 18th century as pneumatization of the anterior ethmoid cells into the roof of the maxillary sinus [8]. We adopted the same definition in reviewing our CT scans. Those cells are closely related to the infundibulum and maxillary sinus ostium [14]. It is suggested that if they are diseased or extremely large, they can obstruct the natural drainage pathway of the maxillary sinus predisposing to infection [14]. Haller's cell prevalence varies widely as well, with the highest reported by Bolger in 1991 as he considered any cell located beneath the ethmoid bulla, the lamina papyracea, or the orbital floor as Haller's cell [6]. In his report, he found no difference in the incidence of Haller's cell between patients with rhinosinusitis and patients without [6]. This was not the case with Stammberger and Wolf [38], who considered the presence of Haller's cell as a predisposing factor for recurrent and refractory maxillary sinusitis. This was also suggested by Kayalioglu et al. [21], who found a higher incidence of Haller's cell among those with sinus disease.

Onodi cell, however, was first described by Adolf Onodi in 1910 and was initially defined as a posterior ethmoid cell that pneumatizes laterally or superiolaterally to the sphenoid sinus [39]. In 1995, the anatomic terminology group defined the Onodi cell as the most posterior ethmoid cell that pneumatizes laterally and superiorly to the sphenoid sinus and is intimately associated with the optic nerve [40].

Their clinical significance is very important as they may expose the optic nerve tract and put the nerve at risk during surgery [7]. Thus, their preoperative identification is extremely helpful in the prevention of inadvertent injury to the optic nerve [7].

\section{Maxillary sinus}

Maxillary sinus hypoplasia is a rare anatomical variation of the sinonasal region [41]. Bolger et al. in 1990 proposed a classification system for maxillary sinus hypoplasia into three types based not only on the small size of the maxillary sinus but also on the development of the uncinate process and its effect on the infundibulum [42].

In our series, we did not adopt this classification and our aim was just to find the prevalence of maxillary sinus hypoplasia of any type in our population.

Sirikci et al. [43], defined maxillary hypoplasia as maximal horizontal or vertical maxillary sinus size less than $50 \%$ of the relevant orbital size. We have adopted the same definition in our study [43].

The prevalence of maxillary sinus hyperplasia in our study group was $5 \%$, which falls within the previously reported range (Table 4).

However, the clinical significance of maxillary sinus hypoplasia does not only lie on the fact that it might be misdiagnosed as sinusitis but also on the accompanying anatomical changes such as medialization of the medial orbital wall and underdevelopment or absence of the uncinate process, which both can lead to difficulty in finding the maxillary sinus ostium and accidental penetration of the orbit during ESS if not recognized preoperatively [4].

Maxillary sinus septa was defined by Selcuk et al. [29] as presentation of bony septum within maxillary sinus and classified them according to their location (anterior or posterior) and their position horizontal, vertical, or 
oblique), and their number (multiple or solitary). In our series, we adopted the definition of presentation of maxillary sinus septum regardless of its location, position, or number.

The incidence of maxillary sinus septa in our study was within the reported range of 1-28\%. Maxillary sinus septa could be primarily due to defect during the embryonic life or secondarily as a result of tooth loss during the process of maxillary sinus pneumatization [44,45]. Kennedy et al. [46] and Stammberger [47] reported that septa might interfere with ESS of the maxillary sinus.

\section{Frontal sinus}

Precise knowledge of the frontal sinus anatomy is necessary before attempting ESS because of its close relationship with other anatomical structures, such as the anterior skull base or the orbit [48].

Frontal agenesis (aplasia) is when there is complete absence of the frontal sinus. Our definition of frontal hypoplasia is when the frontal sinus is not crossing the imaginary line passing through the middle of the orbit longitudinally or not higher than the superior orbital rim roof.

Hypoplastic and aplastic frontal sinuses were identified in a total of $34.2 \%$ of our CT scans. Failure to identify hypoplastic or aplastic frontal sinus may lead to accidental skull base penetration during surgery [48].

\section{Conclusion}

Considering the wide range of variations in the anatomy, each paranasal sinus case should be planned individually and carefully to avoid dreadful complications and maximize patients' benefit.

There is an obvious wide range of prevalence among all anatomical variations. Our results generally were found to fall into those reported ranges with exception to the higher prevalence of pneumatized crista galli and paradoxical middle turbinate. This can be attributed to many factors such as our sample size of patients, the investigator error, possible differences in the CT imaging techniques, and ethnic variations.

Because of the differences in various populations, identification of anatomic variations within the paranasal sinuses in every individual patient with sinonasal disease is substantially important to ensure safe and complete surgery.

\section{Conflicts of interest}

There are no conflicts of interest.

\section{References}

1 Güler C, Uysal IÖ, Polat K, Salk I, Müderris T, Koşar MI. Analysis of ethmoid roof and skull base with coronal section paranasal sinus computed tomography. J Craniofac Surg. 2012; 23:1460-1464.

2 Zinreich SJ. Rhinosinusitis: radiologic diagnosis. Otolaryngol Head Neck Surg 1997; 117:S27-S34

3 Aygun N, Zinreich SJ. Imaging for functional endoscopic sinus surgery. Otolaryngol Clin North Am 2006; 39:403-416.

4 Midilli R, Aladağ G, Erginöz E, Karci B, Savaş R. Anatomic variations of the paranasal sinuses detected by computed tomography and the relationship between variations and sex. Kulak Burun Bogaz Ihtis Derg 2005; 14:49-56.

5 Jaworek JK, Troć P, Chrzan R, Sztuk S, Urbanik A, Walocha J. Anatomic variations of the septation within the sphenoid sinus on CT scan images an initial report. Przegl Lek 2010; 67:279-283.

6 Bolger WE, Butzin CA, Parsons DS. Paranasal sinus bony anatomic variations and mucosal abnormalities: CT analysis for endoscopic sinus surgery. Laryngoscope 1991; 101(Pt 1):56-64.

7 Zinrech SJ. Functional anatomy and computed tomography imaging of the paranasal sinuses. Am J Med Sci 1998; 316:2-12.

8 Simmen D, Schuknecht B. Computerized tomography of paranasal sinuses - a preoperative check list. Laryngorhinootologie 1997; 76:8-13.

9 Prescher A. Clinical anatomy of the paranasal sinuses. Descriptive anatomy, topography and important variations. HNO. 2009; 57:1039-1050.

10 Becker SS. Preoperative computed tomography evaluation in sinus surgery: a template-driven approach. Otolaryngol Clin North Am 2010; 43:731-751.

11 Badia L, Lund VJ, Wei W, Ho WK. Ethnic variation in sinonasal anatomy on CT-scanning. Rhinology 2005; 43:210-214.

12 Silva LC, Zoppa AL, Fernandes WR, Baccarin RY, Machado TS. Bilateral sinus cysts in a filly treated by endoscopic sinus surgery. Can Vet J 2009; 50:417-420

13 Adeel M, Rajput MS, Akhter S, Ikram M, Arain A, Khattak YJ. Anatomical variations of nose and para-nasal sinuses; CT scan review. J Pak Med Assoc 2013; 63:317-319.

14 Kantarci M, Karasen RM, Alper F, Onbas O, Okur A, Karaman A. Remarkable anatomic variations in paranasal sinus region and their clinical importance. Eur J Radiol 2004; 50:296-302.

15 Fadda GL, Rosso S, Aversa S, Petrelli A, Ondolo C, Succo G. Multiparametric statistical correlations between paranasal sinus anatomic variations and chronic rhinosinusitis. Acta Otorhinolaryngol Ital 2012; 32:244-251.

16 Cho JH, Citardi MJ, Lee WT, Sautter NB, Lee HM, Yoon JH, et al. Comparison of frontal pneumatization patterns between Koreans and Caucasians. Otolaryngol Head Neck Surg 2006; 135:780-786.

17 Pérez-Piñas I, Sabaté J, Carmona A, Catalina-Herrera CJ, JiménezCastellanos J. Anatomical variations in the human paranasal sinus region studied by CT. J Anat 2000; 197(Pt 2):221-227.

18 Zinreich J. Imaging of inflammatory sinus disease. Otolaryngol Clin North Am 1993; 4:533-545.

19 Earwaker J. Anatomic variants in sinonasal CT. Radiographics 1993; 13:381-415.

20 Al-Abri R, Bhargava D, Al-Bassam W, Al-Badaai Y, Sawhney S. Clinically significant anatomical variants of the paranasal sinuses. Oman Med J 2014; 29:110-113.

21 Kayalioglu G, Oyar O, Govsa F. Nasal cavity and paranasal sinus bony variations; a computed tomographic study. Rhinology 2000; 38:108-113.

22 Basić N, Basić V, Jukić T, Basić M, Jelić M, Hat J. Computed tomographic imaging to determine the frequency of anatomical variations in pneumatization of the ethmoid bone. Eur Arch Otorhinolaryngol 1999; 256:69-71.

23 Calhoun KH, Waggenspack GA, Simpson CB, Hokanson JA, Bailey BJ. CT evaluation of the paranasal sinuses in symptomatic and asymptomatic populations. Otolaryngol Head Neck Surg 1991; 104:480-483.

24 Blaugrund SM. Nasal obstruction. The nasal septum and concha bullosa. Otolaryngol Clin North Am 1989; 22:291-306.

25 Goldman JL. The principles and practice of rhinology: a text on the diseases and surgery of the nose and paranasal sinuses. New York: Wiley 1987. 89-95 
26 Takanishi R. The formation of the nasal septum and the etiology of septa deformity. Acta Otolaryngol Suppl 1987; 443:1-154.

27 Ritter FR. The paranasal sinuses: anatomy and surgical technique. St Louis: Mosby 1973. 24-36

28 Mazza D, Bontempi E, Guerrisi A, Del Monte S, Cipolla G, Perrone A, et al. Paranasal sinuses anatomic variants: 64-slice CT evaluation. Minerva Stomatol 2007; 56:311-318.

29 Selcuk A, Ozcan KM, Akdogan O, Bilal N, Dere H. Variations of maxillary sinus and accompanying anatomical and pathological structures. J Craniofac Surg 2008; 19:159-164.

30 Jensen OT, Shulman LB, Block MS, lacono VJ. Report of the sinus consensus conference of 1996. Int J Oral Maxillofac Implants 1998; 13:11.

31 Schaefer SD. Endoscopic total sphenoethmoidectomy. Otolaryngol Clin North Am 1989; 22:727-732.

32 Kennedy DW, Zinreich SJ. The functional endoscopic approach to inflammatory sinus disease: current perspectives and technique modifications. Am J Rhinol 1988; 2:89-96.

33 Laine FJ, Smoker WR. The ostiomeatal unit and endoscopic surgery: anatomy, variations, and imaging findings in inflammatory diseases. AJR Am J Roentgenol 1992; 159:849-857.

34 Tonai I, Baba S. Anatomic variations of the bone in sinunasal CT. Acta Otolaryngol Suppl 1996; 525:9-13.

35 Maru YK, Gupta Y. Concha bullosa: frequency and appearances on sinonasal CT. Indian J Otolaryngol Head Neck Surg 1999; 52:40-44.

36 Shihada R, Luntz M. A concha bullosa mucopyocele manifesting as migraine headaches: a case report and literature review. Ear Nose Throat J 2012; 91:E16-E18.

37 Lloyd GA, Lund VJ, Scadding GK. CT of the paranasal sinuses and functional endoscopic surgery: a critical analysis of 100 symptomatic patients. J Laryngol Otol 1991; 105:181-185.
38 Stammberger $\mathrm{H}$, Wolf $\mathrm{G}$. Headaches and sinus disease: the endoscopic approach. Ann Otol Rhinol Laryngol Suppl 1988; 9:3-23.

39 Onodi A The optic nerve and accessory sinuses of the nose: a contribution to the study of canalicular neuritis and atrophy of the optic nerve of nasal origin. New York: Wood; 1910. 80-81.

40 Stammberger HR, Kennedy DW Anatomic terminology group. Paranasal sinuses:anatomic terminology and nomenclature. Ann Otol Rhinol Laryngol Suppl 1995; 167:7-16.

41 Khanduri S, Agrawal S, Chhabra S, Goyal S. Bilateral maxillary sinus hypoplasia. Case Rep Radiol 2014; 2014:148940.

42 Bolger WE, Woodruff WW Jr, Morehead J, Parsons DS. Maxillary sinus hypoplasia: classification and description of associated uncinate process hypoplasia. Otolaryngol Head Neck Surg 1990; 103(Pt 1):759-765.

43 Sirikci A, Bayazit Y, Gumusburun E, Bayram M, Kanlikana M. A new approach to the classification of maxillary sinus hypoplasia with relevant clinical implications. Surg Radiol Anat 2000; 22:243-247.

44 Chanavaz M. Sinus grafting related to implantology. Statistical analysis of 15 years of surgical experience. J Oral Implantol 1996; 22:119-130.

45 Vinter I, Krmpotić-Nemanić J, Hat J, Jalsovec D. Does the alveolar process of the maxilla always disappear after tooth loss. Laryngorhinootologie 1993; 72:605-607.

46 Kennedy DW, Zinreich SJ, Rosenbaum AE, Johns ME. Functional endoscopic sinus surgery: theory and diagnostic evaluation. Arch Otolaryngol 1985; 111:576-582.

47 Stammberger H. Endoscopic endonasal surgery - concepts in treatment of recurring rhinosinusitis. Part I. Anatomic and pathophysiologic considerations. Otolaryngol Head Neck Surg 1986; 94:143-147.

48 Ozgursoy OB, Comert A, Yorulmaz I, Tekdemir I, Elhan A, Kucuk B. Hidden unilateral agenesis of the frontal sinus: human cadaver study of a potential surgical pitfall. Am J Otolaryngol 2010; 31:231-234. 